\title{
Previous Patient Noncompliance
}

National Cancer Institute

\section{Source}

National Cancer Institute. Previous Patient Noncompliance. NCI Thesaurus. Code C102698.

A previous episode of failure by a patient to follow medical advice, take medication as directed, or adhere to a prescribed course of treatment. 